\title{
Perspectives from comparisons of the Hebrew l-suffix with the Shona $h$-suffix features
}

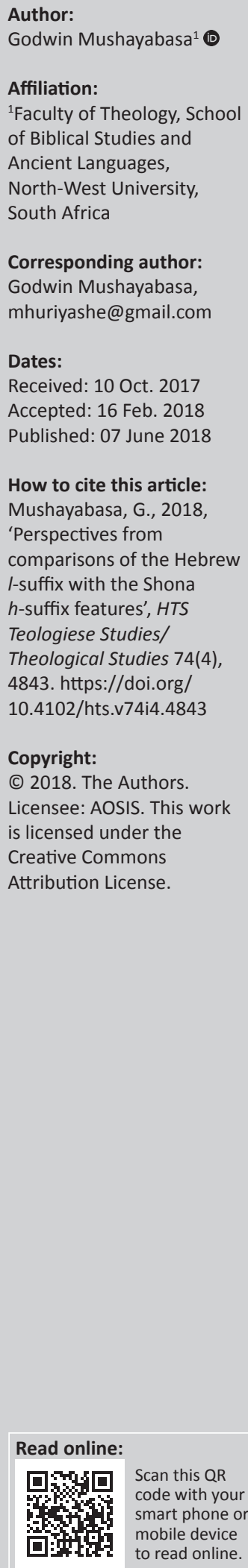

The ethical dative or datious ethicus is a feature used with certain verbs in Biblical Hebrew, which, however, has continued to pose difficulties to grammarians as to its syntactic and semantic references. The feature is also present in other Semitic languages, namely, Syriac and other Aramaic dialects including Persian. Although quite a common feature, the ethical dative is seemingly difficult to translate into English, while its identification as an ethical dative is a widely accepted misnomer. This study attempts to resolve the identification of the feature's grammatical role by seeking to relate it with a similar grammatical feature from Shona, a language from the Central and Southern African group of languages. Although there are some differences between the compared features, the similarities will go a long way to clarify the nature of the Semitic enigma that is currently known as the ethical dative in Hebrew and in other related Semitic languages.

\section{Introduction}

In this study, the Hebrew ethical dative, which is also known as the $l$-suffix feature, will be compared to a similar feature in Shona in terms of the structure as well as semantic reference. Shona is a language found among the Central and Southern African group of languages, also called the Bantu languages. Other related languages from this group may be referenced as well.

\section{The nature of the Shona / $h-/+$ pronominal suffix}

The Shona word form hake is an instance of a linguistic feature that is constructed in a way similar to that of the Semitic lamedh + suffix feature (henceforth $l$-suffix) or what has come to be called the dative of ethic (DE).

The Shona prefix $h$ - that can also be written and pronounced as $z v$-should be understood as a linguistic indicator of the dative, much in the same manner that the Biblical Hebrew $(\mathrm{BH}) \zeta$ indicates direction or possession (as in the words, 'to', 'for' or 'of'). However, when used in a manner similar to that of the $\mathrm{BH}$ ethical dative, the prefix $h$-appears to have no semantic value of its own, serving merely to support the suffix which then refers back to the subject of the verb when used in a DE construction. Because of this function, the whole construction attains a dative character.

The prefix $h$ - is normally completed by a pronominal suffix corresponding to the number and person of the subject (there is no gender distinction in Shona grammar), as well as the class of the subject noun, ${ }^{1}$ to form a word. For example, prefix $h-+$ third person singular (class 1 ) -ake $=$ hake. Other linguistic characterisations of the $h$-suffix will be discussed as comparison is being made to the $\mathrm{BH} l$-suffix in the final sections of this article. Given these definitions, we may define the Shona feature $h$-suffix as roughly corresponding to the Hebrew feature $l$-suffix. Table 1 shows correspondence between the Hebrew and the Shona $\mathrm{DE}^{2}$ feature.

\section{The semantic reference of the Shona dative of ethic (h-suffix)}

There are a few basic semantic references to which the Shona DE feature points. These are:

1. autonomy to perform action by the Actor ${ }^{3}$ or Undergoer (softening of command)

2. distinction of a specific Actor (Undergoer) from another potential Actor

1.Nouns in Shona are grouped into classes of which there are 18 of them. See Stevick and Mataranyika (1965).

2.When referring to the feature in its common occurrence in both Hebrew and Shona, I use the term DE.

3.Identifications of specific role players in a sentence, such as Actor, Subject and Undergoer, will be written with an initial capital letter throughout in this article. 
TABLE 1: Correspondence between the Hebrew and Shona dative of ethic.

\begin{tabular}{|c|c|c|c|c|}
\hline Component items & Prefix & Suffix & Prepositional phrase & Translation \\
\hline Shona & h- & -ako (2 sg.) & hako & _ you (sg.) \\
\hline Hebrew & ל- & $7^{-}$ & לך & To you (sg.) \\
\hline Shona & h- & -enyu (pl.) & henyu & _ you (pl.) \\
\hline Hebrew & ל- & -כן / -כם & לכן / םכל & To you (pl.) \\
\hline
\end{tabular}

3. the achievement of a result despite possible or potential challenges

4. the achievement of a less-than-satisfactory result.

\section{Autonomy to perform the action by the subject or Undergoer}

Stevick and Mataranyika (1965:14) generally state that the word zvangu [a phonetical variant of hangu] can be understood to mean, 'as for me, in my fashion' ${ }^{4}$ From this explanation alone, one notes that the word tends to place some independence of action in the person referred to by the pronominal suffix. Stevick and Mataranyika, however, deviate from this meaning of the Shona DE in further explaining that the effect of using the Shona $h$-suffix is 'to make what one says gentler or more respectful' (1965:14). ${ }^{5}$ The use of the feature in contexts of respect is discussed in later sections below. Typically, the Shona $h$-suffix feature is used in contexts where it gives the impression that some measure of autonomy (or independence) in the action described by the verb is being given to the Actor. In other words, it refers to the fact that the Actor has some freedom or free choice in performing the action (or not performing it). For example, when Naaman, the Assyrian army general, had been healed by Elisha, Naaman bared farewell and Elisha dismissed him with the following words:

\section{2 Ki 5:19}

BDSC $6^{6}$ : Erisha akati, 'Enda ${ }_{[g o]}$ hako $_{[?]}$ norugare $_{[\text {in peace] }}$.

NIV: Elisha said, 'Go in peace'.

In the above example, the verb enda is an imperative to the second-person singular (Naaman). By itself, this verb is a typical equivalent of the English imperative 'Go!' However, when the word $(h-+-a k o=h a k o)$ is added, the speaker gives the impression that he or she is placing the act of going as one that must be carried out at the sole discretion (autonomy) of Naaman, the Syrian army general. This implies that Namaan (the referent of hako) is not under absolute compulsion to go. He has some autonomy to carry out the action. In this regard, the Shona $h$-suffix can be classified as an adverbial, modifying the action of the verb.

Furthermore, it is notable that in commands, such as the one exemplified above, the use of the $h$-suffix feature tends to result in what appears to be a softened command. The

\section{See also Fortune (1985:125)}

5.Ashton (1947:57-58) also identifies use of a similar feature in Swahili. With the Swahili verb -enda (kwenda), Ashton says that the DE feature 'gives force to the meaning' and is used similarly in Shona. Hence, the sentence 'Enda zako' would be interpreted to mean 'be off with you'. This explanation fails to capture the semantics interpreted to mean 'be off with you'. This explanation fails to ca

6.Bhaibheri Dzvene MuChiShona (Holy Bible, Shona Version), elsewhere referred to as BDSC. softening of a command is one effect of vesting the autonomy to act in the commanded person, but it is not the primary intention in using the Shona DE. One should take note that enda hako is not primarily the same as unogona kuchienda [you may go], which may be used as a much more softened command. The feature hako is primarily used to vest some autonomy of performing the action in the actor, but not completely absolving them from the command. This vesting of the actor with autonomy in the action can be observed more clearly in simple statements such as the following:

\section{Common speech act}

$\mathrm{Sh}^{7}$ : Tendai akabva ${ }_{[\text {then] }}$ agara $_{\text {[sat] }}$ hake $_{[?]}$ pasi $_{\text {[down] }}$.

$\mathrm{Tr}^{8}$ : Then Tendai sat down.

In this sentence, the dative + suffix (hake) points to the fact that the Actor, Tendai sat down without necessarily being forced or compelled to do so. Thus, perhaps, we may attempt to translate it into English as 'Then Tendai sat down on his own resolve'. In other words, in carrying out the action, there was no influence on Tendai from any other person or thing.

Because of its reference back to the subject, one may mistakenly understand the $h$-suffix hake/zvake as denoting reflexivity. By viewing this DE as denoting reflexivity, some might be inclined to translate the sentence above as 'Then Tendai sat himself down'. This is, however, not precisely what the Shona DE is communicating in this instance. The $h$-suffix is not suggesting action that the actor performed to himself or for himself, but action that he performed under no duress, without external pressure. In the history of the translation and rendering of the $\mathrm{BH} l$-suffix, the feature has likewise been understood by some as denoting reflexivity. This is the way the feature has been translated in some instances by the Septuagint translator in 1 Samuel 26:11 and by the Revised Standard Version translator in Lamentations 1:4. Naudé (1997:158) has also understood the BH DE as an anaphoric clitic with a reflexive function. However, in a recently published article, ${ }^{9}$ I have demonstrated that the $l$-suffix feature tends to profile aspects motion and seperation with respect to some verbs of motion. Reflexivity is therefore a less likely function of the DE feature, at least as far as both Shona and $\mathrm{BH}$ are concerned.

\section{Contrastive action by an Actor in relation to other Actors}

Another nuance communicated by the $h$-suffix can be observed when it is used to show that an Actor acts autonomously, and also in contradiction to the way that another Actor (or Actors) chose to act. Noss (1995:332, 334335) identifies this function and calls it the contrastive subject focus. This use of the $h$-suffix is demonstrated in the following example:

7.'Sh' is used as an abbreviation for 'Shona'.

8.' $\mathrm{Tr}^{\prime}$ is used as an abbreviation for 'My translation'.

9.Mushayabasa (2017) 


\section{Common speech act}

Sh: John, tora hako udye chingwa ichi, Tendai haachidi.

Tr: John, take this bread and eat, Tendai does not like it.

A typical example from the Shona Version can be taken from Psalm 109:28 as follows:

\section{Psalm 109:28}

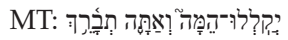

BDSC: Ivo vangatuka havo, asi imi mucharopafadza.

Tr: They may curse (as they please), but you will bless.

In the first example above, the word hako is used to communicate that John is being exhorted or encouraged to eat the bread, irrespective of the fact that Tendai has refused it. In other words, John's action will be in contradiction to another party that may or may not participate in the same action. In that respect, John's action, if he performs, it will be in distinction to Tendai's and hence also autonomous. Similarly, in the second example, the word havo is applied this time to a group of people who autonomously choose to curse the subject, whereas YHWH will rather bless. In that regard, the Actor (Those who may curse) is acting independently, and in contrast to the decisions of another Actor $(\mathrm{YHWH})$ in regard to the same object. It is clear that in this scenario, we still notice a relation with the earlier discussed function of the Shona DE: that of reference to an autonomous action. This nuance whereby distinction is given to the actor in contrast to other actors has been witnessed in other African languages. Thus, Noss (1995:331) notes that, 'In Gbaya usage, the comparable construction also places the accent upon the person who acts, placing his action in contrast or opposition to that of those about him'.

\section{Achievement of a result despite possible or potential challenges}

In other contexts, the Shona $h$-suffix feature can be used to denote that the action represented by the verb was performed or will be performed despite some potential challenges that may hinder the action. One may consider an example where elderly parents send a young person of 12 years with a parcel to a relative in another city, say, which takes about $2 \mathrm{~h}$ bus travel. This is a journey that persons of this age would not normally undertake by themselves. However, when the young person has made the trip, the parents of the child may ask the relative to whom the child has been sent. In reply the relatives will most likely give the following reply:

\section{Common speech act}

Sh: Mukomana akasvika hake zvakanaka.

Tr: The young lad arrived well (despite the high possibility that something bad could have happened to him on the way).

\section{Expression of the achievement of a less-than- satisfactory result}

The feature can also be used to communicate achievement of a less-than-satisfactory result. Hence, when one is asked, 'How was the wedding party?' One may answer with the words: 'Kwanga kuchinakidza zvekuti' (Oh, it was very good), or they may rather say:

\section{Common speech act}

Sh: Kwanga kuchinakidza hako.

Tr: It was fairly exciting (it was exciting but not as much as I would have liked it to be).

When this use of the DE is analysed, one comes to the conclusion that it here primarily serves to identify the lessthan-satisfactory result as distinct from the satisfactory expected norm. ${ }^{10}$

In all the previous functions of the $\mathrm{DE}$, one may observe that the Shona DE serves to highlight some sort of distinction or separation, either in the way an action is performed or is viewed against other actors involved in the action or against a norm.

\section{Relationship of the Shona dative of ethic to the English grammatical construction with modal 'can' or 'may'}

There is a real possibility that one can be tempted to equate the semantic reference of the $h$-suffix with the English modal verbs 'can' and 'may'. Although there is a sense in which the Shona feature may be represented by these modal verbs, there is no formal correspondence between them. The $h$-suffix refers to autonomy to act or an expression of distinction, while the English modal verbs 'can' and 'may' point primarily to possibility or probability of an event happening. ${ }^{11}$ As for the case of modality in Shona, there are specific verbs meant to communicate this aspect of modality such as -gona orkwanisa (pre-verbal modal verbs, just like 'can' and 'may') and -nga- (prefixed to a verb).

The closest relation between the English modal verbs and the Shona $h$-suffix occurs when the English words 'may' or 'can' are understood in the context of giving permission (to act). Naturally, this giving of permission also translates to granting some kind of autonomy to the person receiving that permission. In such instances, the $h$-suffix may indeed approximate to the same semantic references as that of the English modal verbs. But it is best to understand this permission as resulting in the first place from an intention to grant autonomy to the Actor to perform the intended act.

Furthermore, we need to note that with the $h$-suffix, autonomy does not always need to be given by another party. In non-imperative statements, the autonomy to act lies primarily in the Actor themselves. The autonomy is not necessarily given, it is supposedly inherent in the Actor (see '(2) Common speech act' section). In the case of imperative statements, however, the instructor appears to be giving permission to the Actor to act autonomously in the required action.

\section{Similar characterisations have been suggested in Noss (1995:331)}

11.Merriam-Webster (2003). Further, the words may be used for 'permission', a wish or desire. 


\section{Types of verbs that can be used with the $\boldsymbol{h}$-suffix}

As the $h$-suffix primarily functions to confer autonomous action, or to express distinction, it can therefore be used with virtually any verbs of action. It can be used with both transitive and intransitive verbs, in the passive as well as in the active forms of these verbs. However, the application of the feature with passive verbs, though possible, remains on the odd side of the grammar and thus occurs less frequently. When the passive is used, the semantic reference is an encouragement to the person on whom the action is made (Patient) to receive the action graciously.

One marked difference between the use of the Shona DE feature and the one encountered in the Semitic languages, especially Syriac, is that the former cannot normally be used with verbs that denote action resulting in negative circumstances or states. This also includes negative events that are accidental. For example, we can say:

\section{Common speech act}

Sh: Akabva arara hake.

Tr: Then she slept.

But in the following cases, we cannot normally use the $h$-suffix, as shown here:

\section{Common speech act}

Sh: Akabva afa zvake*.12

Tr: Then she died.

Or:
9. Common speech act
Sh: Vabirwa havo mari yavo*.
Tr: Their money has been stolen from them.

Note that in Syriac, it is possible to express all the above example sentences using the $l$-suffix feature. In illustration 8 , the ungrammaticality in using the $h$-suffix happens because in the case of death, the understanding is that one seldom has the freedom and hence autonomous license to die. Similarly, in the case of illustration 9 regarding theft, one will not normally exercise autonomous and willing action in an act that will lead to their loss or harm.

\section{The notion of respect}

Because the Shona $h$-suffix generally denotes or gives autonomy (to act) to the Actor with some nuance of distinction, it tends to be associated with cases in which some respect or politeness is expressed in the way commands are made to an Actor. As a result, as we have briefly noted above, the use of the feature tends to soften the command so that the mood of the speaker giving the command is not interpreted as being totally authoritative, especially when such a command is given to a more respectable or senior person than the person giving it. For this reason, Stevick and Mataranyika (1965:14) have stated that one of the functions of this feature is to denote respect. This semantic reference is, however, not the primary reference of the Shona DE.

\section{Analysis of similarities and differences between the $\mathrm{BH}$ and the Shona dative of ethic features}

We have noted in the foregoing discussion that the Shona $h$-suffix can be made to function with almost any action verb. In contrast, the $\mathrm{BH} l$-suffix can only be used with a limited range of verbs. Although no agreement exists at the moment as to the types of verbs affected in Semitic languages, the general tendency has been to confine the use of the Hebrew DE to intransitive verbs. ${ }^{13}$ Even then, not all intransitive verbs can be observed to require the use of the feature. While passive and reflexive verbs may take the feature in Syriac, BH generally eschews the feature with such verbs.

From the results of recent studies, the observation of the present author has been that in Semitic languages, the $l$-suffix tends to refer to the notions of motion and separation. But as the feature is mostly found with verbs of motion, the aspect of motion is already communicated by the verb. ${ }^{14}$ It is therefore the aspect of separation from a point of interest that is the one clearly communicated by the Semitic l-suffix. Muraoka (1978) has also noted that the Hebrew l-suffix:

$[b]$ asically ... serves to convey the impression on the part of the speaker or author that the subject establishes his own identity, recovering or finding his own place[] by determinedly dissociating himself from his familiar surroundings. Notions of isolation, loneliness, parting, seclusion, or withdrawal are often recognizable ... (p. 497)

As far as the DE in Shona is concerned, we have noted that it denotes autonomy of action or contrastive action or simply distinction of a specific action in relation to a norm. It is plain from Muraoka's description that the 'dissociating himself from his familiar surrounding ...' is a feature much akin to that of a Shona subject that is given autonomy of action, or of identifying a specific act as distinct from an expected norm. In this respect therefore, we may note that there would be quite close semantic characteristics between the Hebrew and the Shona DE, especially at the conceptual level. Secondly, the $\mathrm{DE}$ in both these languages may be observed to refer to what we may call an 'aspect of independence' that arises with the Actor or Theme. In Shona, the Actor is given some independence in the action to be taken. Similarly, in $\mathrm{BH}$, the Actor gains some independence from a point of interest when they engage in motion that separates them from such a point of interest. However, in some contexts, especially involving imperative commands, it is difficult to see the $\mathrm{BH} \mathrm{DE}$ as suggesting the notion of autonomy of action to the recipient

13.This is discussed at greater length in Mushayabasa (2017). Joosten (1989:473-474) confines the DE feature in Classical Syriac to intransitive verbs, though in a recent publication on the matter, Joosten has made some indications towards viewing the DE as equally applying with some tranition in the pool of words with which the Hebrew DE occurs in the Old Testament.

14.See also Noss (1995:330). 
of the command. Therefore, the sense in which the notion of separation (and motion) is applied to both the $\mathrm{BH}$ and the Shona DE cases may differ in certain contexts. This is to be expected because these languages are not of the same family.

Following further on this discussion, we thus are inclined to identify the Shona DE as an adverbial, as far as it modifies the actor's action, that is, the verb. If this is the case with the Shona DE, we should also be persuaded that the Hebrew DE, which also tends to provide a certain perspective on the actor's action, should be viewed as having an adverbial function. In both Shona and Hebrew, this is strengthened by the fact that the $l$-suffix and the $h$-suffix features are juxtaposed to the verb rather than the actor. In fact, in Shona, the DE feature can be separated from the subject by other subclauses, without impacting on its meaning. The feature is virtually unusable in non-predicative (or non-verbal) constructions. Further, the DE cannot be translocated easily from its post verbal position, both in Shona and in other Semitic languages. In both languages, the feature should come immediately after the verb it modifies - and not before it. $^{15}$ This attribute of the order from verb to adverb has a conceptual bearing on the meaning of the adverb. Conceptually, it can be taken to mean that the DE cannot be meaningful unless it is with reference to a certain action.

From all these analyses, one comes to the conclusion that the meaning of the Hebrew $l$-suffix feature cannot be deduced by means of componential analysis. This means that one cannot simply analyse the constituent components of the construction and integrate their semantic references to provide its meaning. Thus, for example, the meaning cannot be arrived at by reasoning that לך (= preposition $ל$ + suffix 7$)$, will give the meaning 'to you.' The meaning of the $h$-suffix cannot be deduced by this type of componential analysis. In the same way, the l-suffix should not be expected to be understood in that manner.

In the third place, the $l$-suffix seems to serve to indicate motion and transition from one state to another where it is used with stative verbs. ${ }^{16} \mathrm{BH}$ has a few instances of the use of the DE feature with stative verbs. This phenomenon, involving stative verbs, occurs more frequently in Classical Syriac. However, it is completely absent in the contexts of the Shona $h$-suffix.

Finally, one can observe that there are several nuances of the $h$-suffix that are almost totally absent in $\mathrm{BH}$ or the Semitic languages in general. These include use of the DE for expression of an achievement of a less-than-satisfactory result and distinction of an actor from other potentially interested actors.

As an important aspect of the present study, one may observe that at the conceptual level, the semantic frames of

15.See Joosten (1989:474). The same author, however, cites an exceptional case in one of the Syriac New Testament texts, which might be because of the incorporation of Greek elements into the Syriac language (see also Noss 1995:328).

16.Mushayabasa (2017). autonomy and separation are not far apart from each other. An entity's separation from another produces a situation of autonomy and autonomy results when an entity is separated from the control of another. The action of departing, hence separating from a point of interest, has an eventual effect of placing the Actor in an autonomous position, in relation to his point of interest (Source). Yet, these similarities cannot be pressed too far given that the languages involved here are widely separated temporally, geographically and genealogically.

From the above similarities and differences, it becomes apparent that the DE feature in Shona is not an exact semantic copy of the Hebrew DE feature. Similarly, in a recent study of the feature between $\mathrm{BH}$ and Classical Syriac, I have found that although there are common major features in the way the DE is used between these two language corpuses, there are nevertheless also significant differences - even though both fall into the Semitic language family. To that end, the meaning of the feature cannot be generalised across different languages and language families. This could be the danger that lurks in Noss's study of the meaning of the feature in a wide range of African languages (Noss 1995). While one may establish the main uses and semantic references of the feature, there are dangers of missing other unique uses, such as those we have found in the use of the $h$-suffix.

\section{Acknowledgements}

The author's acknowledgements go to the session that listened to the reading of this article at the SASNES conference held at the University of Pretoria, 05-06 September 2017.

\section{Competing interests}

The author declares that he or she has no financial or personal relationships which may have inappropriately influenced him or her in writing this article.

\section{References}

Ashton, E.O., 1947, A Swahili grammar: Including intonation, Longman, London.

Bhaibheri Dzvene MuChiShona, 2006, Holy Bible, Shona Version (Bhaibheri Dzvene MuChiShona), Biblica, viewed 15 November 2017, from https://www.bible.com/ en-GB/versions/32

Fortune, G., 1985, Shona grammatical constructions, vol. 1, 3rd edn., Mercury Press, Harare.

Joosten, J., 1989, 'The function of the so-called dativus ethicus in classical Syriac', Orientalia 58(4), 473-492.

Joosten, J., 1996, The Syriac language of the Peshitta and Old Syriac versions of Matthew: Syntactic structure, inner-Syriac developments and translation technique, studies in Semitic languages and linguistics, Brill, Leiden.

Merriam-Webster Inc., 2003, Merriam-Webster's collegiate dictionary, 11th edn., Merriam-Webster Inc., MA.

Muraoka, T., 1978, 'On the so-called dativus ethicus in Hebrew', The Journal of Theological Studies, New Series 29(2), 495-498.

Mushayabasa, G., 2017, 'Tracing the use and semantic contribution of the I-suffix construction in Biblical Hebrew and Classical Syriac', Journal for Semitics 26(2), 772-804.

Naudé, J.A., 1997, 'The syntactic status of the ethical dative in Biblical Hebrew', Journal for Semitic Studies 9(1), 129-165.

Noss, P.A., 1995, 'The Hebrew post-verbal lamed preposition plus pronoun: Discourse features in the light of some African languages', The Bible Translator 46(3), 326335. https://doi.org/10.1177/026009359504600304

Stevick, E.W. \& Mataranyika, M., 1965, Shona basic course, Department of State, Washington, DC 